\title{
Effects of Constant Darkness and Constant Light on Circadian Organization and Reproductive Responses in the Ram
}

\author{
Francis J. P. Ebling, ${ }^{* 1}$ Gerald A. Lincoln, ${ }^{*}$ Franziska Wollnik, $\dagger^{2}$ and \\ Norah Anderson* \\ *MRC Reproductive Biology Unit, 37 Chalmers Street, Edinburgh, EH3 9EW, \\ United Kingdom, and tDepartment of Neurobiology and Physiology, \\ Northwestern University, Evanston, Illinois 60208
}

\begin{abstract}
The relationship between circadian rhythms in the blood plasma concentrations of melatonin and rhythms in locomotor activity was studied in adult male sheep (Soay rams) exposed to 16-week periods of short days ( $8 \mathrm{hr}$ of light and $16 \mathrm{hr}$ of darkness; LD 8:16) or long days (LD 16:8) followed by 16-week periods of constant darkness (dim red light; DD) or constant light (LL). Under both LD 8:16 and LD 16:8, there was a clearly defined 24-hr rhythm in plasma concentrations of melatonin, with high levels throughout the dark phase. Periodogram analysis revealed a 24-hr rhythm in locomotor activity under LD 8:16 and LD 16:8. The main bouts of activity occurred during the light phase. A change from LD 8:16 to LD 16:8 resulted in a decrease in the duration of elevated melatonin secretion (melatonin peak) and an increase in the duration of activity corresponding to the changes in the ratio of light to darkness. In all rams, a significant circadian rhythm of activity persisted over the first 2 weeks following transfer from an entraining photoperiod to $\mathrm{DD}$, with a mean period of $23.77 \mathrm{hr}$. However, the activity rhythms subsequently became disorganized, as did the $24-\mathrm{hr}$ melatonin rhythms. The introduction of a 1-hr light pulse every $24 \mathrm{hr}$ (LD 1:23) for 2 weeks after 8 weeks under DD reinduced a rhythm in both melatonin secretion and activity: the end of the 1-hr light period acted as the dusk signal, producing a normal temporal association of the two rhythms. Under LL, the 24-hr melatonin rhythms were disrupted, though several rams still showed periods of elevated melatonin secretion. Significant activity rhythms were either absent or a weak component occurred with a period of $24 \mathrm{hr}$. The introduction of a 1-hr dark period every $24 \mathrm{hr}$ for 2 weeks after 8 weeks under LL (LD 23:1) failed to induce or entrain rhythms in either of the parameters. The occurrence of $24-$ hr activity rhythm in some rams under LL may indicate nonphotoperiodic entrainment signals in our experimental facility. Reproductive responses to the changes in photoperiod were also monitored. After pretreatment with LD 8:16, the rams were sexually active; exposure to LD $16: 8$, DD, or LL resulted in a decline in all measures of reproductive function. The decline was slower under DD than LD 16:8 or LL. Conversely, after pretreatment with LD 16:8, the rams were sexually regressed, and exposure to LD 8:16, DD, or LL resulted in redevelopment of the reproductive axis; the rate of
\end{abstract}

1. Present address, to which all correspondence should be addressed: Consortium for Research in Developmental and Reproductive Biology, The University of Michigan, 300 N. Ingalls Building, Ann Arbor, Michigan 48109-0404.

2. Present address: Fakultät für Biologie, Universität Konstanz, Postfach 55 60, D-7750 Konstanz 1 , West Germany. 
development was similar in all three treatments. The overall results illustrate that in the Soay ram the circadian organization of melatonin and activity rhythms is disrupted during prolonged exposure to DD and LL. Reproductive regression or recrudescence occurs under these constant conditions, apparently dictated by the immediate photoperiodic history.

Sheep are seasonal breeders, and there is considerable evidence that their photoperiod influences the timing of the reproductive cycle through the pattern of melatonin secretion from the pineal gland (Almeida and Lincoln 1982; Karsch et al., 1984). Studies in ewes in which endogenous melatonin secretion has been abolished by pinealectomy and replaced with timed infusions of melatonin, suggest that it is the duration of the nocturnal melatonin peak that conveys information about day length to the reproductive axis (Bittman et al., 1983; Bittman and Karsch, 1984; Wayne et al., 1988). The additional importance of the phase of the melatonin rhythm in conveying day length information remains to be resolved (Watson-Whitmyre and Stetson, 1983). Although light can directly suppress melatonin secretion, the daily rhythm is not simply induced by the environmental light-dark (LD) cycle. Studies demonstrating that melatonin rhythms persist under constant photoperiod conditions indicate that the rhythm is generated endogenously (Rollag and Niswender, 1976; Almeida and Lincoln, 1984a); thus, it appears that the environmental LD cycle acts to entrain this endogenous rhythm and to set the duration of the nocturnal rise such that it reflects the duration of the dark phase (Lincoln et al., 1985). The mechanism by which light both entrains and directly suppresses pineal melatonin secretion is poorly understood. We have previously observed that melatonin rhythms free-run for up to 10 days under both constant dark (DD) and constant light (LL); however, the duration of that experiment was too short to determine the subsequent effects of these free-running melatonin rhythms on reproductive function (Almeida and Lincoln, 1984a).

There are technical limitations associated with collecting blood samples over sufficiently long time periods to define accurately the circadian mechanisms underlying the control of melatonin secretion. This problem has led to the study of rhythms that can be monitored continuously and that may be closely linked to the circadian control of melatonin secretion. In the Syrian hamster, for example, the photoperiod induces changes in phase and duration of the daily bouts of wheel-running activity closely correlated with changes in the rhythms in pineal melatonin and changes in reproductive activity (Elliott, 1976; Eskes and Zucker, 1978; Ellis and Turek, 1979).

These methods have never been applied to studies in sheep, where it is possible to measure the hourly changes in the blood concentrations of melatonin for several days, giving a direct indication of the pattern of melatonin secretion. The aims of the present study were therefore as follows: to investigate the relationship between the 24-hr rhythms in blood concentrations of melatonin and in activity in sheep kept under short days (LD 8:16), long days (LD 16:8), constant darkness (DD), and constant light (LL); and to measure the reproductive responses in sheep exposed to these different experimental photoperiods. 


\section{MATERIALS AND METHODS}

\section{ANIMALS}

Two groups of adult male Soay sheep ( $n=8$ and 7) were housed indoors in individual pens in light-proof sheds at the Animal Breeding Research Organisation, Roslin, Scotland, U.K. Food and water were provided ad libitum; rams were fed a pelleted concentrate diet by means of individual hoppers that were refilled at 3-4 day intervals. Water buckets were refilled daily between 0800 and $1600 \mathrm{hr}$. Lighting was provided by white fluorescent strip lights giving approximately 160 lux at the level of the rams' eyes, and a $15-\mathrm{W}$ red bulb was left on permanently to allow blood sampling and maintenance during the dark periods. Before the experiment, both groups of rams were exposed to a photoperiod of LD 16:8 for 12 weeks to allow acclimatization to the indoor housing. Four rams died during the experiment (see Fig. 7, below), three from complications arising from the occurrence of urinary calculi, a possible side effect of the ad libitum concentrate diet.

\section{PHOTOPERIOD TREATMENTS}

In all experiments, short days were LD 8:16, with lights-on at $0800 \mathrm{hr}$. Long days were LD 16:8, with lights-on at $0800 \mathrm{hr}$. Constant darkness was dim red light, and constant light was continuous fluorescent illumination. Following the acclimatization period, the rams in Group 1 were exposed to changes in photoperiod every 16 weeks, as shown in Figure 1. The sequence was short days (LD 8:16), long days (LD 16:8),
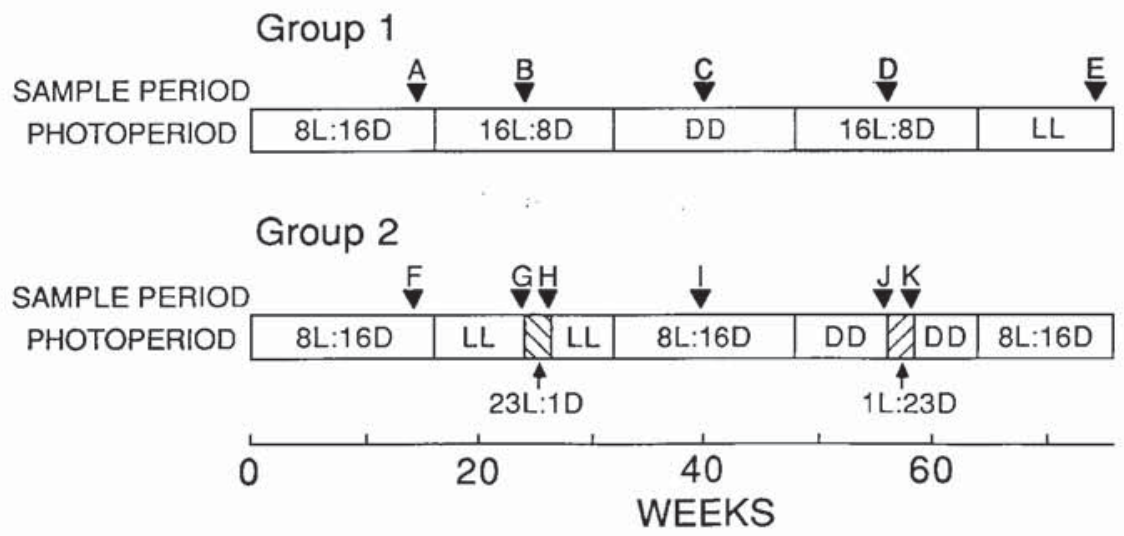

Figure 1. Experimental design. Groups of 1.5 -year-old Soay rams ( $n=8$ or 7 per group) were pretreated for 12 weeks with LD 16:8, then transferred to the photoperiod treatments indicated. $8 \mathrm{~L}: 16 \mathrm{D}$, short days of $8 \mathrm{hr}$ light and $16 \mathrm{hr}$ dark; $16 \mathrm{~L}: 8 \mathrm{D}$, long days of $16 \mathrm{hr}$ light and $8 \mathrm{hr}$ dark; DD, constant dim red light; LL, continuous light. Letters (A to K) indicate occasions on which blood samples were collected hourly for $49-56 \mathrm{hr}$ for the determination of melatonin patterns. The rams in Group 2 were exposed to $1 \mathrm{hr}$ darkness per $24 \mathrm{hr}$ after 8 weeks on the LL photoperiod (23L:1D, sampling period $\mathrm{G}$ to $\mathrm{H}$ ) and to $1 \mathrm{hr}$ light per $24 \mathrm{hr}$ after 8 weeks on the DD photoperiod (1L:23D, sampling period $\mathrm{J}$ to $\mathrm{K}$ ). 
constant darkness (DD), long days (LD 16:8), and finally constant light (LL). The rams in Group 2 were exposed to changes in photoperiod every 16 weeks, as shown in Figure 1, with the sequence as follows: short days, constant light, short days, constant darkness, and finally short days. In this group, a 1-hr dark pulse was introduced every $24 \mathrm{hr}$ (LD 23:1) for a 2-week period after 8 weeks under LL, and a 1-hr light pulse was introduced every $24 \mathrm{hr}$ (LD 1:23) for a 2-week period after 8 weeks under DD.

Throughout the study, activity was monitored for four of the rams in each group using a reflective photorelay (RS Components Ltd., Corby, Northants, U.K.) coupled to an Esterline Angus event recorder (Model A620X, International Recorders Ltd., Berkhamsted, Hertfordshire, U.K.). The photorelay reflected an infrared beam across the pen of each ram approximately $30 \mathrm{~cm}$ above floor level. Each time the beam was broken by movement of the animal it produced a deflection on the paper of the chart recorder. Damage to the recording device led to a loss of results for some sections of the experiment.

Melatonin rhythms were measured on nine selected occasions as indicated in Figure 1. Blood samples were collected at hourly intervals for 49-56 hr using an indwelling jugular catheter inserted on the day before the study. For the rams in Group 2, the blood sampling periods on LL and DD (sample periods G and J, respectively, Fig. 1) overlapped the first $24 \mathrm{hr}$ of the LD 23:1 and LD 1:23 photoperiods. Serial blood samples were also collected from the rams in Group 2 during the last $49 \mathrm{hr}$ of the 2-week dark and light pulse treatments (sampling periods $\mathrm{H}$ and $\mathrm{K}$, respectively, Fig. 1). In the cases where the jugular cannula became blocked or broken, it was replaced where possible, but when a series of blood samples was not collected, the results for the entire 24 -hr period were omitted (e.g., Figs. 6 a and $6 \mathrm{~b}$, below, no data).

The reproductive changes in the rams were monitored by measuring the diameter of the testes and the intensity of the sexual skin flush at biweekly intervals (Lincoln and Davidson, 1977) and by collecting blood samples at weekly intervals by jugular venipuncture for the measurement of the concentrations of folliclestimulating hormone (FSH).

\section{RADIOIMMUNOASSAYS}

Plasma melatonin concentrations were measured using the radioimmunoassay described by Rollag and Niswender (1976). Antiserum R1055 was used at a final dilution of $1: 256,000$. The lower limit of detection was $10 \mathrm{pg} / \mathrm{ml}$ and the intra-assay coefficients of variation (CVs) based on duplicates of quality control plasma pools were $15.8 \%$ (low, $65 \mathrm{pg} / \mathrm{ml}$ ) and $12.0 \%$ (high, $250 \mathrm{pg} / \mathrm{ml}$ ); interassay CVs for these plasma pools were $26.6 \%$ and $14.6 \%$, respectively. Plasma FSH concentrations were measured by the radioimmunoassay system of McNeilly et al. (1976). The reference standard was NIH-FSH-S18, and the lower limit of detection was $5 \mathrm{ng} / \mathrm{ml}$. The mean intra-assay $\mathrm{CV}$ based on low, medium, and high plasma pools was $12.3 \%$, and the mean interassay $\mathrm{CV}$ was $14.7 \%$. 


\section{DATA ANALYSIS}

Activity records were prepared by mounting the daily chart record for each ram beneath the record for the preceding day to create a continuous picture of the ram's activity through the various changes in photoperiods. The charts have been double plotted to emphasize trends. Portions of the activity records were analyzed by the chi squared periodogram method (Sokolove and Bushell, 1978). This method has proven to be reliable for the detection of circadian periodicities, even in the presence of high levels of noise (Wollnik and Döhler, 1986). For the LD 8:16 and LD 16:8 photoperiods, the activity records for the 10 days immediately preceding the first blood sampling period for each group (sampling periods A and F, Fig. 1) were analyzed. The analyses for the DD and LL photoperiods used the first 10 days of records following transfer from the entraining photoperiod of either LD 8:16 or LD 16:8. Likewise, analyses for LD 23:1 and LD 1:23 treatments also used the first 10 days of activity records for these photoperiods. The 10-day sections of the charts were divided into 8-min bins. Each bin was scored from 0 (no pen deflections) to 4 (continuous activity for the entire $8 \mathrm{~min}$ ). The digitized data were analyzed on a microcomputer. $Q_{p}$ values above $\chi_{p-1}^{2}(0.001)$ indicate significant periodicity at approximately the 0.01 level of confidence (Sokolove and Bushell, 1978). The period lengths determined by this method for groups of rams on entraining photoperiods (LD 8:16 or 16:8) and subsequently on a constant photoperiod (DD) were compared using the Wilcoxon signed-ranks test (Siegel, 1956).

The melatonin profiles for each ram were analyzed for the existence of melatonin using a nonparametric method (Lincoln et al., 1985). This technique provides an objective method for distinguishing time periods when plasma melatonin concentrations are high and when they are low, in cases where there are insufficient cycles of data to permit a more rigorous time series analysis. The analysis consisted of the following steps: (1) The plasma melatonin concentrations for each sampling period for each ram were ranked, then divided into classes of 10,15 , or $20 \mathrm{pg} / \mathrm{ml}$ to obtain a frequency distribution of values. The width of these classes depended on the absolute plasma melatonin concentrations: they were chosen such that there were approximately 10 classes of values for each ram. (2) The frequency distribution was used to assess any discontinuity between high and low values; if there was no discontinuity evident the median value was determined. (3) A runs test (Siegel, 1956) was performed on each profile to determine whether there was significant clustering of the melatonin values above and below the discontinuity or median. (4) Where significant clustering was observed, melatonin peaks were defined as periods containing four or more consecutive values above the discontinuity or median, a criterion previously adopted by Almeida and Lincoln (1982). Shorter runs separated from a peak of four or more consecutive values by only a single low value were considered to be an extension of the same peak. Selected comparisons of the duration of melatonin peaks were made using paired $t$ tests for photoperiod treatments in which rams showed significant melatonin peaks (see Table 2 , below).

Reproductive responses to the photoperiods for each ram were analyzed by 
fitting a straight line using linear regression to the plasma FSH values over the first 8 weeks of each photoperiod treatment and to the values for testicular diameter over the first 12 weeks of each photoperiod. These end points were chosen to encompass the periods of maximal change as indicated from previous studies in which Soay rams were transferred from long days (LD 16:8) to short days (LD 8:16) or vice versa (Lincoln and Davidson, 1977), or treated with a constant-release melatonin implant (Lincoln and Ebling, 1985). The slope of the fitted line indicates the rate of change of each parameter. Significant differences in mean rates of change under different photoperiods were detected by analysis of variance with repeated measures (ANOVA) for the rate of increase in testis diameter (Group 1); results were found by the Student's (between group) or paired $t$ test (within group) when only a single comparison could be made.

\section{RESULTS}

\section{ACTIVITY RHYTHMS RELATED TO PHOTOPERIOD}

Long-term activity records (double-plotted) from a representative ram from each group are shown in Figure 2. Activity records in relation to melatonin patterns are illustrated from representative rams in Figures 4 (Group 1) and 5 (Group 2). Clearly defined rhythms in activity were evident in all rams kept under entraining photocycles of either short days (LD 8:16) or long days (LD 16:8). Visual inspection of the activity records (Figs. 2, 4, and 5) indicates a crepuscular pattern of activity under short and long days, with the main bouts of activity early and late in the light phase. Periodogram analysis revealed a period close to that of the 24-hr entraining photocycle (range, 23.87-24.00 hr; Table 1; Fig. 3).

When the rams were transferred from long days to DD (Group 1) or from short days to DD (Group 2), significant activity rhythms persisted for at least the first 10 days (Figs. 2, 4b, and 5b). Periodogram analysis (Fig. 3) revealed a shortening of the period under DD (Table 1) with a mean $( \pm S E M)$ period of $23.77 \pm 0.08 \mathrm{hr}$. This was significantly shorter than that on LD 8:16 or 16:8 $(23.97 \pm 0.03 \mathrm{hr})(p<0.05$, Wilcoxon signed-ranks test). Visual inspection of the activity records suggests that free-running activity rhythms did not persist in most rams after prolonged exposure to DD. However, the introduction of a 1-hr light pulse every $24 \mathrm{hr}$ to the rams in Group 2 restored a significant activity rhythm (Figs. $2 \mathrm{~b}$ and $5 \mathrm{~b}$ ) with a period length ranging from 24.13 to $24.27 \mathrm{hr}$. The amplitude of these periodogram peaks $\left(Q_{p}\right)$ was considerably lower than those when the rams were previously on LD 8:16.

Activity rhythms were very variable in rams transferred from long or short days to LL. In no cases did a significant rhythm persist with a period of less than $24 \mathrm{hr}$; however, in several rams a low-amplitude rhythm with a period close to $24 \mathrm{hr}$ occurred (Fig. 3; see also Fig. 4c). Some rams had significant rhythms with short periodicities (e.g., $5.87 \mathrm{hr}$ ). These appeared on the activity charts as short bouts of activity (see LL treatments; Figs. $2 \mathrm{~b}$ and $5 \mathrm{a}$ ). The introduction of a 1-hr dark pulse 
(a)

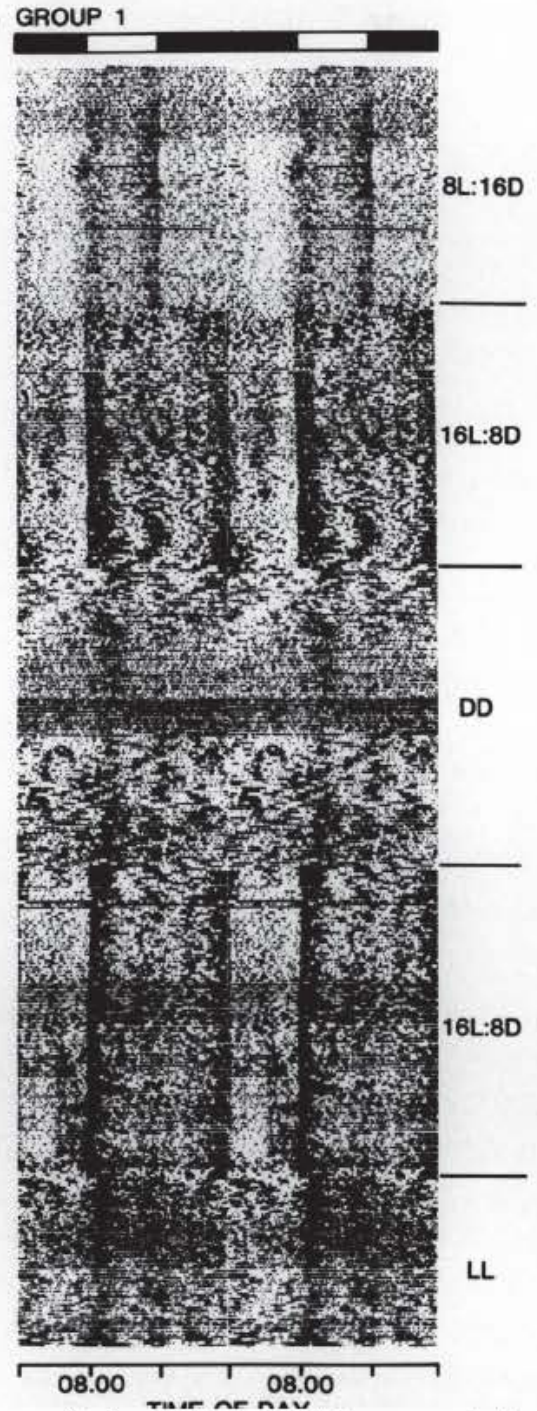

GROUP 2

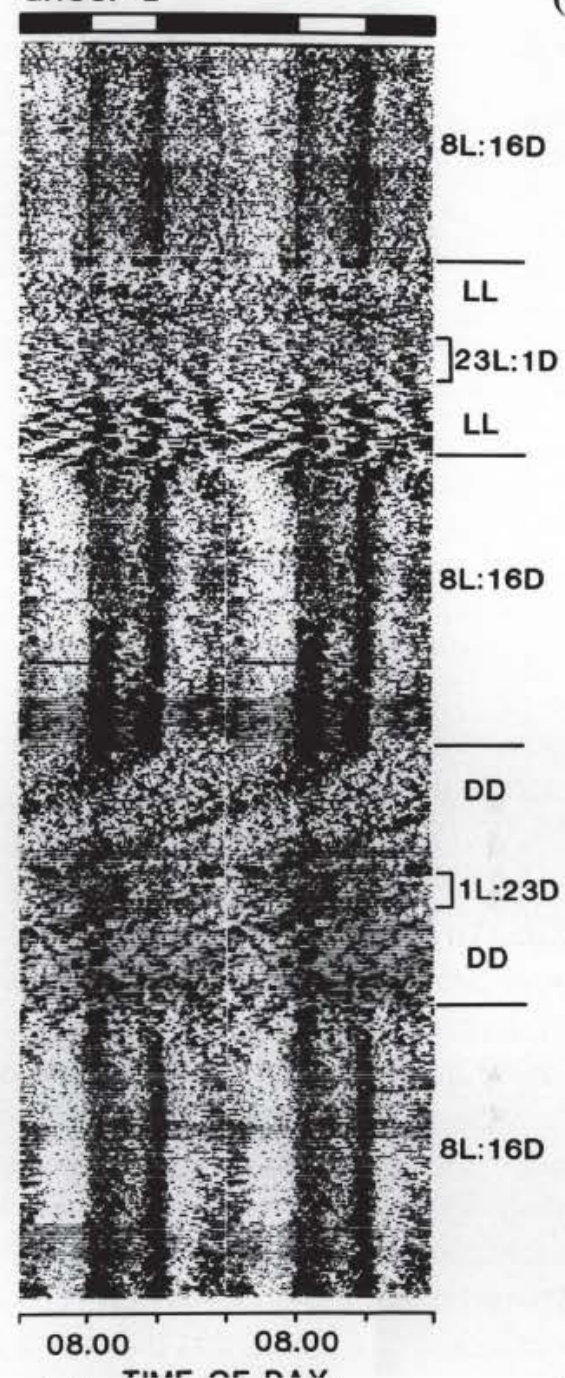

(b)

FIGURE 2. Long-term activity records for a representative ram from each group exposed to the sequence of photoperiod changes indicated on the right. (Abbreviations are defined in the legend to Fig. 1.) The records were produced using an Esterline Angus event recorder connected to a reflective photorelay operated when the the animal crossed an infrared beam. The data for each day are presented in vertical sequence to produce a continuous record and are double plotted for clarity. Segments of data that were lost due to breakage of the recording device are omitted. (a) A ram from Group 1. (b) A ram from Group 2. Rams were exposed to each of the photoperiod treatments for 16 weeks, as shown in Figure 1. In addition, the ram in Group 2 received a 1-hr dark pulse per $24 \mathrm{hr}$ for 2 weeks, starting 8 weeks after transfer to LL treatment, and a 1-hr light pulse per $24 \mathrm{hr}$ for 2 weeks, starting 8 weeks after transfer to DD. 
EBLING, LINCOLN, WOLLNIK, AND ANDERSON

TABLE 1. Summary of Periodogram Analysis

\begin{tabular}{|c|c|c|c|c|}
\hline $\begin{array}{c}\text { Ram } \\
\text { number }\end{array}$ & Photoperiod & $\begin{array}{l}\text { Period length } \\
\text { (hr) }\end{array}$ & Photoperiod & $\begin{array}{l}\text { Period length } \\
\text { (hr) }\end{array}$ \\
\hline S20 & LD $8: 16^{b}$ & 23.87 & $\mathrm{DD}^{d}$ & 23.33 \\
\hline S21 & LD $8: 16^{b}$ & 24.00 & $\mathrm{DD}^{d}$ & 23.60 \\
\hline S26 & LD $8: 16^{b}$ & 24.00 & $\mathrm{DD}^{d}$ & 23.33 \\
\hline S27 & LD $8: 16^{b}$ & 24.00 & $\mathrm{DD}^{d}$ & 23.20 \\
\hline S29 & LD $16: 8^{c}$ & 24.00 & $\mathrm{DD}^{d}$ & 23.73 \\
\hline S30 & LD $16: 8^{c}$ & 24.00 & $\mathrm{DD}^{d}$ & 23.73 \\
\hline S 34 & LD $16: 8^{c}$ & 23.87 & $\mathrm{DD}^{d}$ & 24.00 \\
\hline S35 & LD $16: 8^{c}$ & 24.00 & $\mathrm{DD}^{d}$ & 23.60 \\
\hline
\end{tabular}

Note. See legend to Figure 1 for explanation of photoperiod abbreviations.

${ }^{a}$ Limit of resolution is $8 \mathrm{~min}(0.13 \mathrm{hr})$. Period indicated is for the largest activity peak (maximum $Q_{p}$ ) revealed in the periodogram analysis.

${ }^{b}$ Ten-day activity record analyzed preceding sampling period I (see Fig. 1).

${ }^{c}$ Ten-day activity record analyzed preceding sampling period B (see Fig. 1).

${ }^{d}$ Activity record analyzed for the first 10 days following transfer to DD.

every $24 \mathrm{hr}$ after 8 weeks on LL (Group 2) did not appear to influence the activity patterns of the rams (e.g., Fig. 5a).

\section{MELATONIN RHYTHMS IN RELATION TO PHOTOPERIOD AND ACTIVITY}

Representative melatonin patterns for rams in each group for the various photoperiod treatments are shown in Figures 4 and 5 in relation to activity records for the individual rams. The timing of melatonin peaks for individual rams for each of the sampling periods (Fig. 1) are shown in Figures 6a (Group 1 rams) and 6b (Group 2 rams). Group mean melatonin concentrations are also shown as an index of synchrony of melatonin patterns between rams. In all the rams in both groups, significant melatonin peaks occurred on LD 8:16 and 16:8 (Table 2; Fig. 6). The duration of these melatonin peaks closely resembled the duration of the dark period (Table 2). Occasionally, a significant melatonin peak would occur during only one of the two dark periods covered by the 50 -hr blood sampling period (e.g., Fig. 6a, sampling period A; Fig. 6b, sampling periods $\mathrm{F}$ and I).

In the rams in Group 1, transfer from LD 8:16 (sampling period A) to 16:8 (sampling period B) resulted in a significant decrease in the duration of melatonin peaks (Table 2; Figs. 4a and 6a). The activity records for the corresponding period illustrated a clearly defined rhythm in activity under LD 8:16 with the main bouts of activity early and late in the light phase and the end of the activity period closely synchronized to the onset of increased melatonin secretion. The change to LD 8:16 led to an extention of the period of locomotor activity corresponding to the increased duration of the light phase; the end of the activity period was again sychronized to the onset of increased melatonin secretion, both having changed in timing by $8 \mathrm{hr}$ in relation to the change in the time of lights out (Fig. 4a).

Significant melatonin peaks persisted in three of four rams 8 weeks after transfer from LD 16:8 to DD (sampling period C: Table 2; Fig. 6a). The duration of these 
GROUP 1
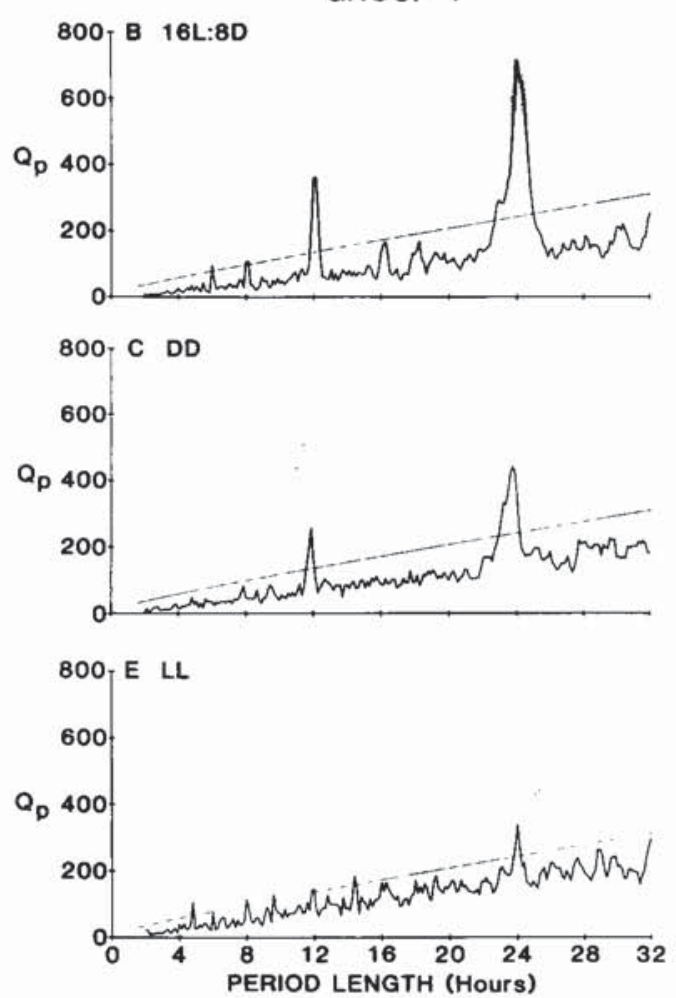

GROUP 2
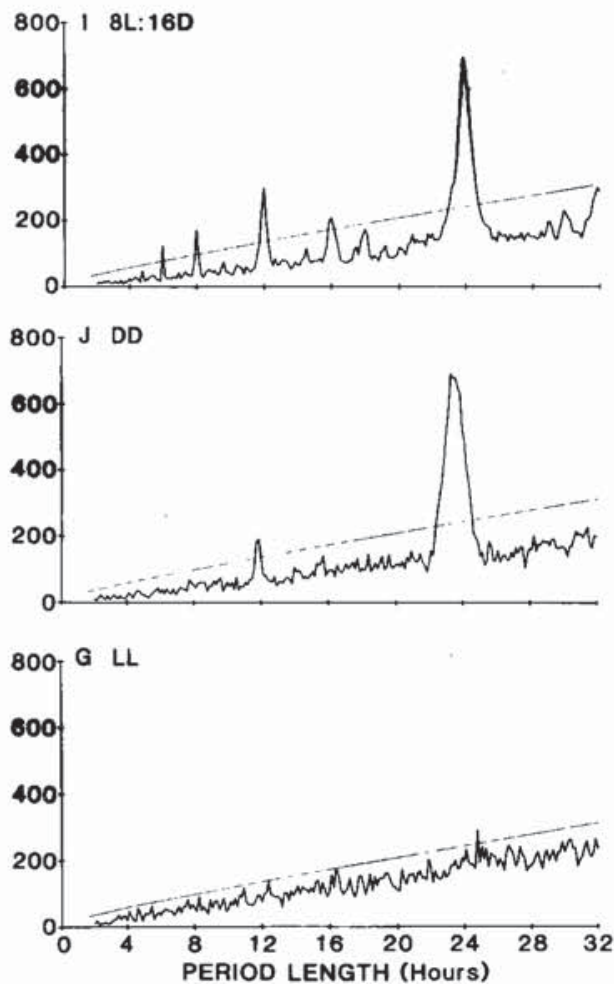

FIGURE 3. Representative periodogram analyses for a ram from Group 1 (left panels) and a ram from Group 2 (right panels). Top left: Ram on LD 16:8, calculated for the 10-day period preceding sampling period B (see Fig. 1). Middle left: First 10 days on DD following transfer from LD 16:8. Bottom left: First 10 days on LL following transfer from LD 16:8. Top right: Ram on LD 8:16, calculated for the 10-day period preceding sampling period I (see Fig. 1). Middle right: First 10 days on DD following transfer from LD 8:16. Bottom right: First 10 days on LL following transfer from LD 8:16. Solid rising line in all panels indicates $p<0.001$. Photoperiod treatments are defined in legend to Figure 1.

peaks did not differ significantly from that previously observed on LD 16:8 (Table 2), and the absence of a clear pattern in group mean melatonin concentrations (Fig. 6a) demonstrates the lack of synchrony between individuals. The following long-day treatment synchronized short-duration melatonin peaks (sampling period D: Fig. 6a) and restored a clear activity pattern (Fig. 4c). Significant melatonin peaks persisted after 8 weeks following transfer from $\mathrm{LD} 16: 8$ to $\mathrm{LL}$, but these were of very variable duration and of variable periods between successive peak onsets (sampling period $\mathrm{E}$ : Figs. 6a and 4c).

In the rams in Group 2, there was a well-defined rhythm in plasma melatonin concentrations on the initial photoperiod treatment of LD 8:16 (sampling period F: Figs. $6 \mathrm{~b}$ and $5 \mathrm{a}$ ). After 8 weeks under LL, there was no evidence of a rhythm in melatonin peaks, though plasma melatonin concentrations were not consistently suppressed (sampling period G: Figs. $6 \mathrm{~b}$ and $5 \mathrm{a}$ ). The introduction of a 1-hr dark 


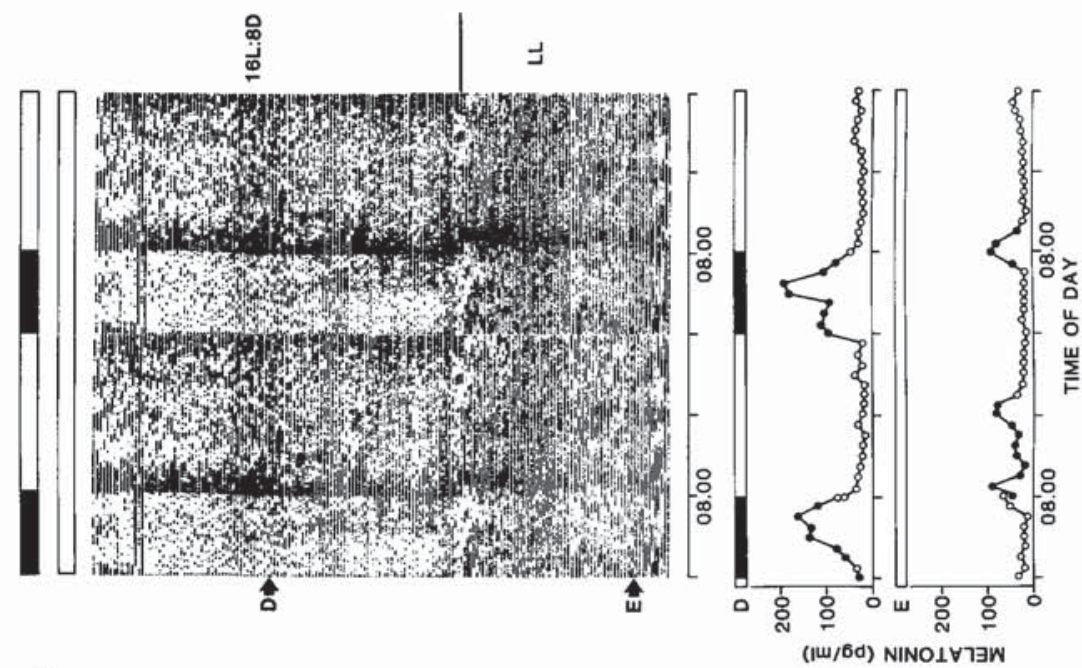

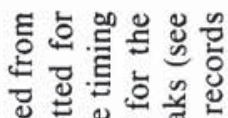

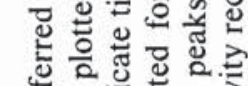

뉸

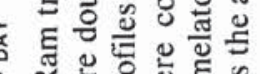

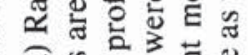

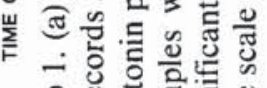

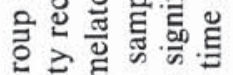
ง ซั

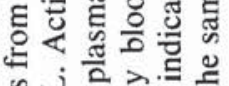

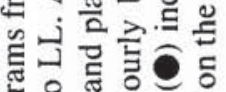

(e)

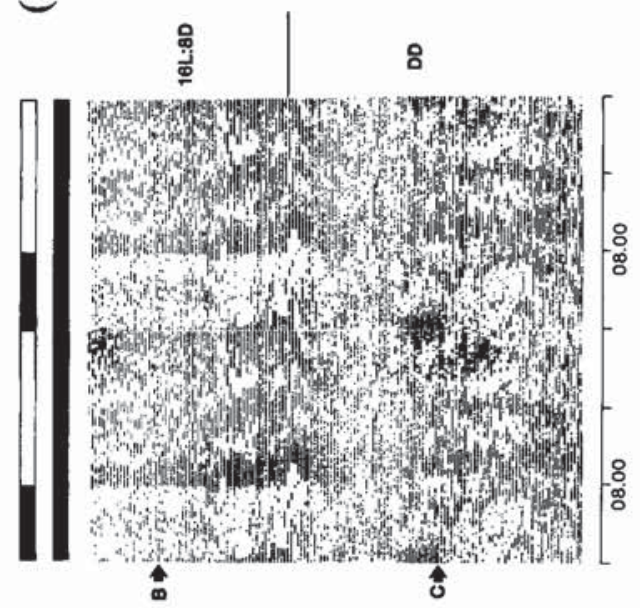

อ

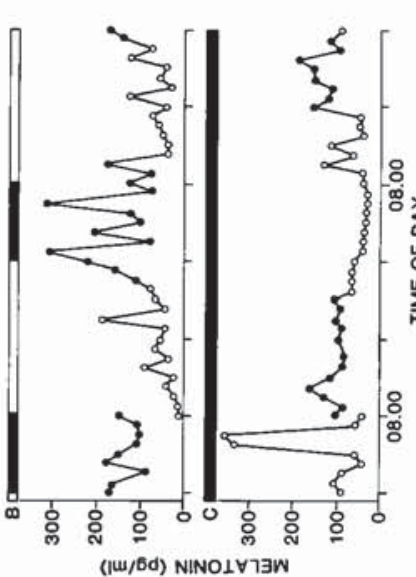

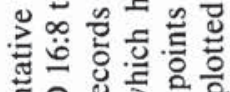
들

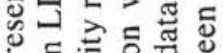

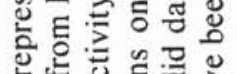

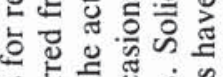
政势 过 는

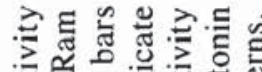

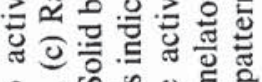
$\circ$ i ธิดิ

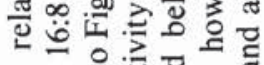
.

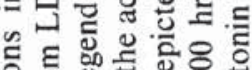
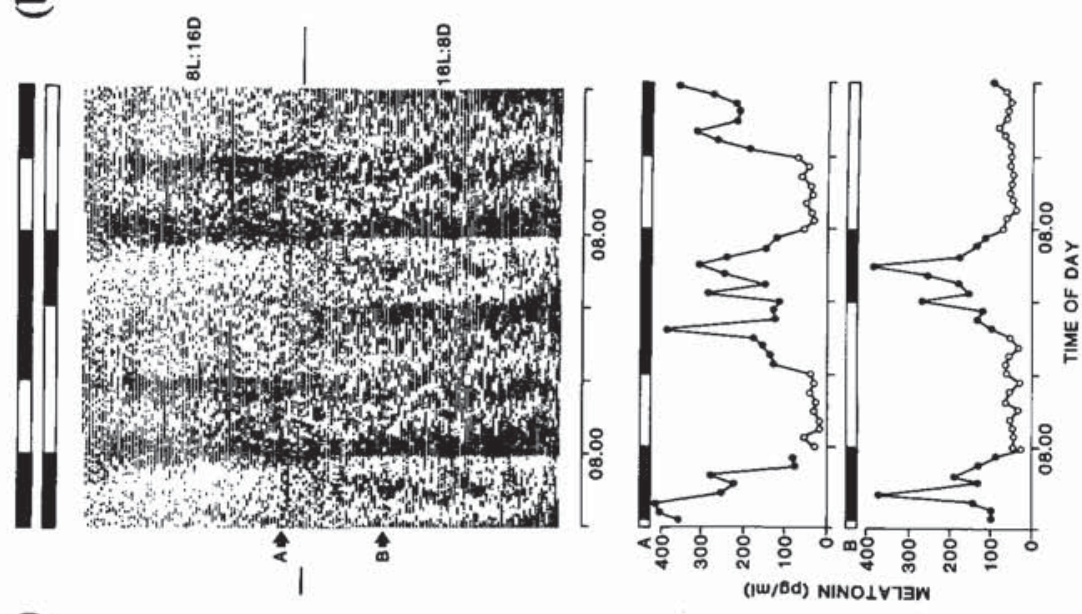
을융 웡 氙记

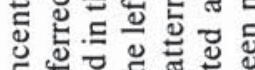

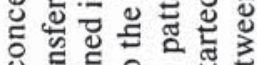

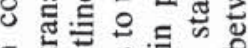

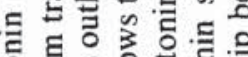

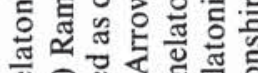
司. ๑

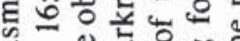
ส

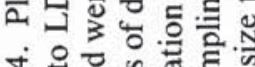

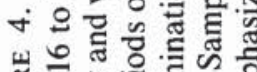
㟧

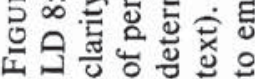


(a)

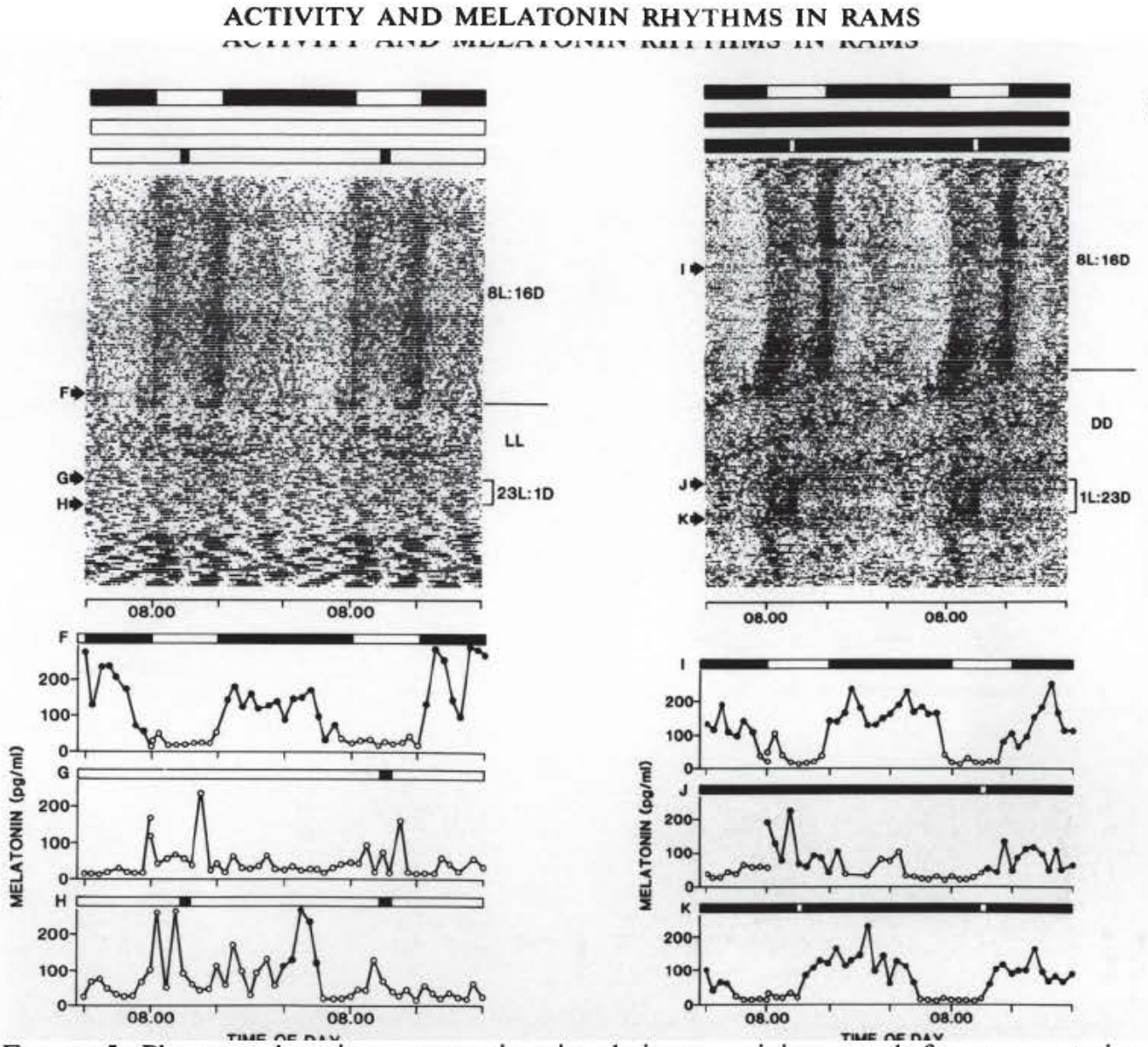

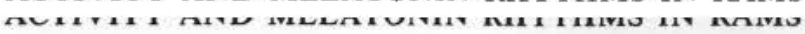

FIGURE 5. Plasma melatonin concentrations in relation to activity records for representative rams from Group 2. (a) Ram transferred from LD 8:16 to $\mathrm{LL}$, then briefly to LD 23:1 as indicated to the right of the activity record. (b) Ram transferred from LD 8:16 to DD, then briefly to LD 1:23 as indicated. Activity records are double plotted. Solid bars above the activity records and melatonin patterns indicate timing of periods of darkness. Arrows to the left of the activity records indicate occasions on which hourly blood samples were collected for the determination of the melatonin patterns depicted below the activity records. Solid data points (-) indicate significant melatonin peaks (see text). Sampling for melatonin began at $0800 \mathrm{hr}$ on each occasion; however, melatonin patterns have been plotted on the same time scale as the activity records to emphasize relationships between the melatonin and activity patterns.

pulse for 14 days at this stage did not induce the reappearance of a rhythm in melatonin concentrations, although three out of six rams now had significant melatonin peaks of short duration (sampling period $\mathrm{H}$ : Fig. 6b; Table 2). The subsequent short-day treatment restored long-duration melatonin peaks (sampling period I: Table 2; Fig. 6b). After 8 weeks on DD, significant melatonin peaks persisted in five of six rams (sampling period J: Fig. 6b), with a significantly reduced duration (Table 2). These peaks were not synchronized between rams, as indicated by the lack of a clear pattern in mean melatonin concentrations. The introduction of a 1-hr light pulse for 14 days after 8 weeks under DD resulted in the reappearance of a synchronized 
(a)
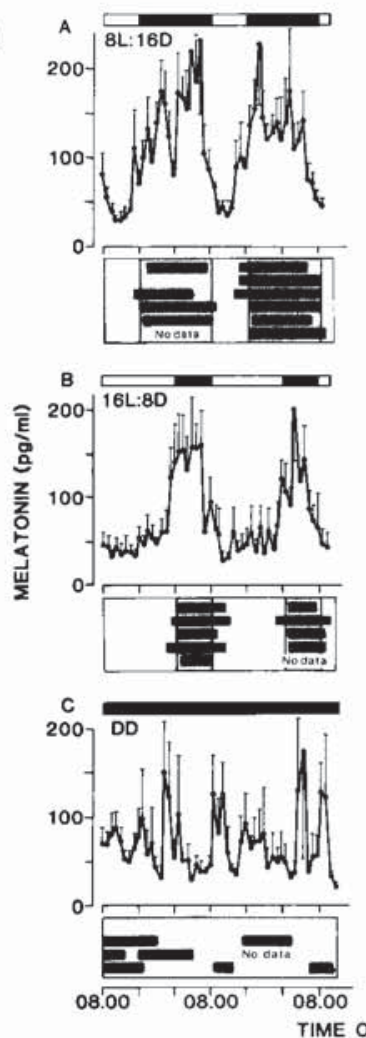
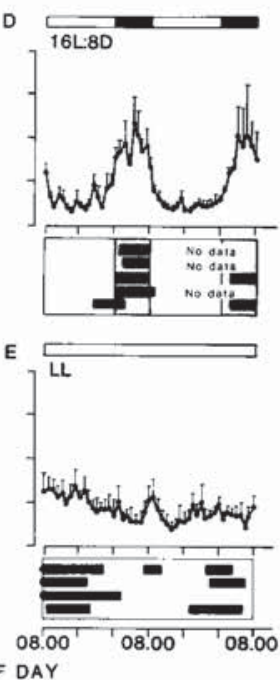
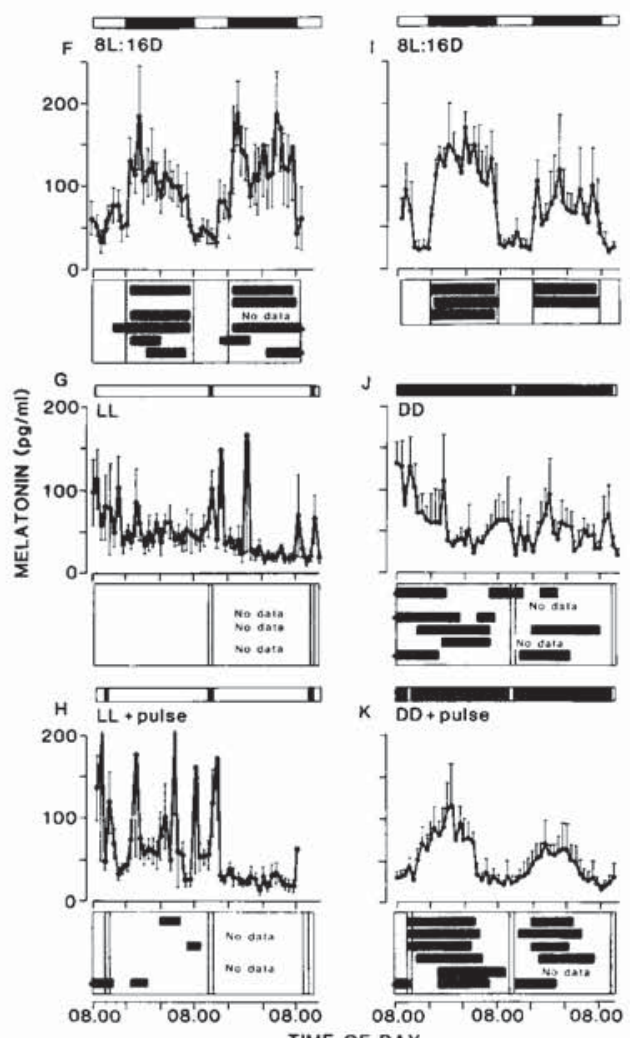

FIGURE 6. Solid blocks represent timing of significant melatonin peaks (see text) for individual rams on each of the sampling occasions for (a) Group 1 and (b) Group 2, plotted in relation to the LD cycle (darkness indicated by shaded background). The group mean ( $\pm S E M$ ) plasma melatonin concentrations for each sampling occasion are plotted above to provide an index of synchrony of melatonin rhythms between individual rams. Open and solid bars above the melatonin patterns also indicate light and dark periods, respectively. The timing of the sampling periods (A to K) and details of photoperiod treatments are shown in Figure 1. "No data" indicates periods when insufficient blood samples were obtained for analysis of melatonin peaks.

rhythm between rams in plasma melatonin concentrations and induced a significant rhythm in activity. The onset of the melatonin peaks occurred during or shortly after the 1-hr light pulse and at the end of the activity period (e.g., Fig. 5b); this temporal relationship is similar to that previously observed under LD 8:16 and 16:8.

\section{REPRODUCTIVE RESPONSES}

The long-day acclimatization period synchronized testicular regression in all rams. In the rams in Group 1, the initial short-day treatment induced rapid testicular recrudescence (Fig. 7a), and rapid testicular regression occurred during the subsequent long-day treatment (Fig. 7a). Reproductive activity began to increase before the end of the 16-week long-day treatment, as indicated by the increase in plasma 
TABLE 2. Effect of Photoperiod on Presence and Duration of Melatonin Peaks

\begin{tabular}{llcc}
\hline Sampling period $^{a}$ & Photoperiod $^{a}$ & $\begin{array}{c}\text { Number of } \\
\text { rams with peaks }\end{array}$ & Duration (hr) \\
\hline Group 1 & LD 8:16 & $\mathbf{6 / 6}$ & $15.7 \pm 0.7$ \\
A & LD 16:8 & $\mathbf{S / 5}$ & $9.4 \pm 1.0^{b}$ \\
B & DD & $\mathbf{3 / 4}$ & $8.9 \pm 1.3$ \\
C & LD 16:8 & $\mathbf{5 / 5}$ & $7.4 \pm 0.3^{b}$ \\
D & LL & $\mathbf{4 / 4}$ & $12.4 \pm 2.6$ \\
E & & & \\
Group 2 & LD 8:16 & $\mathbf{6 / 6}$ & $13.4 \pm 2.1$ \\
F & LL & $\mathbf{O} / 7$ & - \\
G & LD 23:1 & $3 / 6$ & $4.3 \pm 0.3$ \\
H & LD 8:16 & $3 / 3$ & $15.2 \pm 0.2$ \\
I & DD & $\mathbf{5 / 6}$ & $11.6 \pm 1.3^{c}$ \\
J & LD 1:23 & $\mathbf{6 / 6}$ & $13.5 \pm 1.0$ \\
K & & & \\
\hline
\end{tabular}

Note. Values are means $\pm S E M$.

${ }^{a}$ See Figure 1 for explanation of abbreviations.

${ }^{b} p<0.001$ versus LD 8:16 (A), paired $t$ test.

${ }^{c} p<0.05$ versus LD 8:16(I), paired $t$ test.

FSH and testis diameter (Fig. 7a). Rapid testicular recrudescence occurred during exposure to DD, and then testicular involution occurred during subsequent exposure to long days. Finally, rapid recrudescence also occurred during exposure to constant light after long-day treatment (Fig. 7a). The rates of testicular growth in the rams in Group 1, when pretreated with long days, did not differ significantly on LD 8:16, DD, or LL $(1.3 \pm 0.1$ vs. $1.1 \pm 0.1$ vs. $1.3 \pm 0.1 \mathrm{~mm} /$ week, mean $\pm S E M)$. Likewise, the rates of increase in plasma FSH did not differ in the Group 1 rams on DD or LL following $\mathrm{LD}$ 8:16 pretreatment.

In the rams in Group 2, after the initial rapid testicular development on LD 8:16, rapid testicular regression occurred during the subsequent LL treatment (Fig. 7b). Although the rams were exposed to a 2-week period of LD 23:1 after 8 weeks of the LL treatment, the reproductive responses appeared to be very similar to those in the rams in Group 1 concurrently exposed to long days (Fig. 7a). For example, following an initial period of testicular regression on LL and LD 1:23, an increase in plasma FSH concentrations occurred (Fig. 7b), a comparable pattern to that in the Group 1 rams concurrently exposed to LD 16:8. After the 16-week period of short days, during which rapid testicular recrudescence occurred, the rams were exposed to DD. The rate of testicular regression was significantly slower than that previously seen on $\mathrm{LL}(-0.6 \pm 0.2 \mathrm{vs}$. $-0.9 \pm 0.1 \mathrm{~mm} /$ week) following short-day pretreatment and was significantly slower than that seen in the rams in Group 1 transferred from short days to long days $(-1.2 \pm 0.1 \mathrm{~mm} /$ week $)$. In addition, reproductive activity became desynchronized between rams, as indicated by the large variance in mean testis diameter, the decrease in plasma FSH to intermediate levels, and the reemergence of the sexual flush in several of the rams (Fig. 7b). This lack of synchrony suggests that the brief period of exposure to LD 1:23 after 8 weeks on DD did not provide a major entrainment cue for reproductive activity. 
(a)

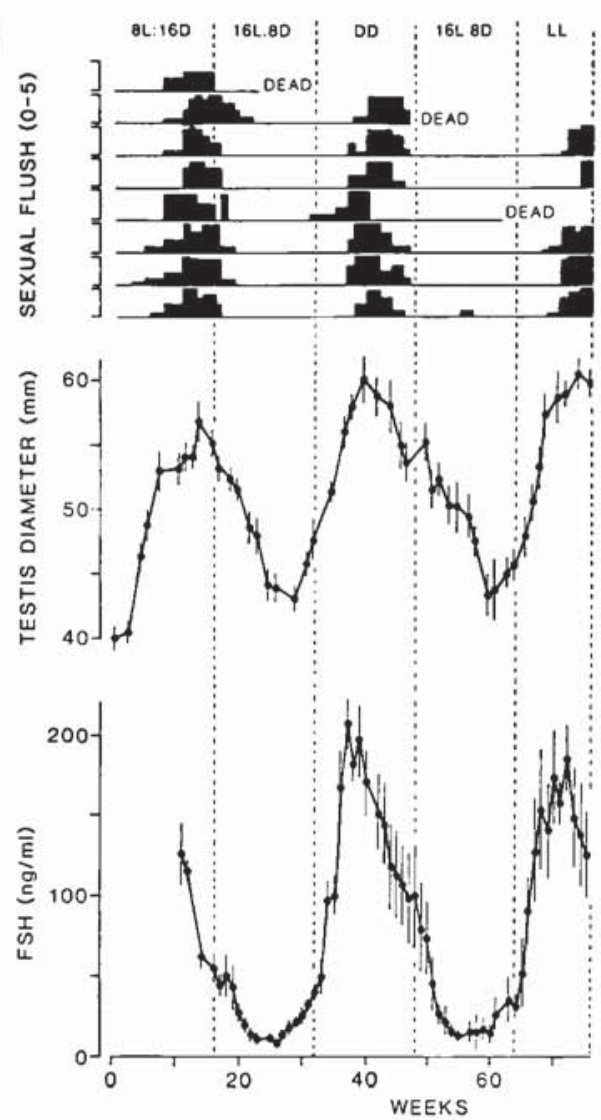

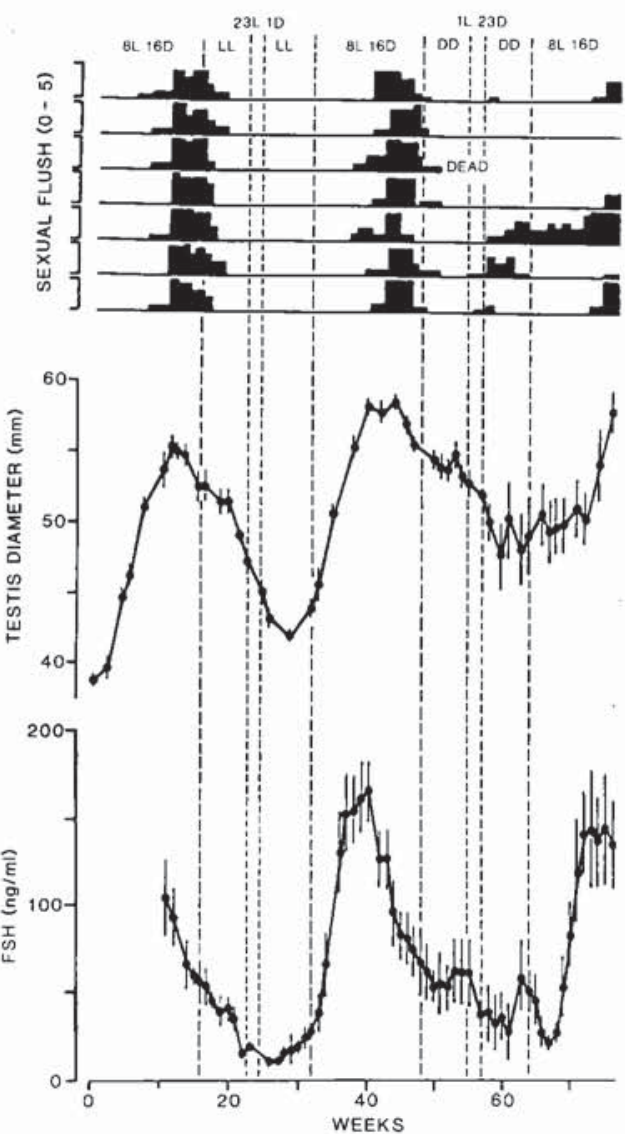

(b)

FIGURE 7. Reproductive activity in (a) Group 1 rams and (b) Group 2 rams. For each group, the sequence of photoperiod treatments is indicated at the top (see legend to Fig. 1 for explanation of abbreviations and further details). In the top panels, solid blocks indicate timing and intensity of inguinal sexual flush for each individual ram. The middle panels show mean $( \pm S E M)$ testis diameter. The lower panels depict mean $( \pm S E M)$ plasma FSH concentrations.

\section{DISCUSSION}

Previous studies in sheep have demonstrated that melatonin rhythms persist for up to 10 days in animals transferred from standard 24-hr LD cycles to DD (Rollag and Niswender, 1976; Almeida and Lincoln, 1984a; Lincoln et al., 1985). These studies provided clear evidence that the melatonin rhythm is generated endogenously but is normally entrained to the environmental LD cycle such that the period of increased melatonin secretion coincides with the dark phase. This normal pattern of melatonin secretion is seen in the current study in the rams held under LD 8:16 or 16:8, where the duration of the melatonin peak corresponded closely to the duration of the dark period. The observation that the melatonin rhythm was poorly defined after 8 weeks under DD indicates that the rhythm did not persist indefinitely but disappeared after prolonged exposure to DD. This may be consistent with the hypothesis that the 
generation of the melatonin rhythm results from the interaction of two or more groups of oscillators (Illnerova and Vanecek, 1982; Lincoln et al., 1985). The absence of a zeitgeber in the long-term could result in dissociation of these different oscillators, which are normally coupled to produce a single melatonin peak per $24 \mathrm{~h}$, resulting in the variable durations and periodicities of the melatonin peaks observed in the current study. Clearly, the 50 -hr blood sampling window does not permit this hypothesis to be resolved because it would require many cycles of data for the free-running components of the melatonin rhythm to be demonstrated. In anticipation of this problem, activity rhythms were monitored to provide a continual assessment of the circadian organization of the rams under the different photoperiodic treatments. In hamsters, splitting of the rhythm of wheel-running behavior under constant illumination provides evidence that two groups of oscillators underlie the endogenous rhythm of locomotor activity (Turek et al., 1982).

Activity rhythms were clearly evident in the Soay rams during the LD 8:16 and $16: 8$ photoperiods. These rhythms reflect increased activity during the light phase in relation to feeding and drinking. They also reflect behavioral interactions between neighboring animals, since the rams were housed together in a single photoperiod room, albeit in separate pens. Diurnal variations in grazing and rumination in sheep kept under natural conditions have been observed previously (Hughes and Reid, 1951; Gordon and McAlistair, 1970). In a study of feeding behavior in rams maintained on LD 8:16 and 16:8, it was found that the greater proportion of feeding occurred during the light phase (Eisemann et al., 1984). Also, Hunsaker and Wolynetz (1979a, 1979b) have described a crepuscular pattern of activity in sheep held under controlled conditions with major bouts of activity following lights-on and preceding lights-off. The periodogram analysis revealed that a component of the activity pattern free-ran for several days under DD, indicating that at least part of the rhythm is generated endogenously. However, the pattern of activity appeared to become fragmented during prolonged exposure to DD, such that a clear rhythm could not be detected after 8 weeks on this treatment. The rhythm in melatonin secretion was also poorly defined at this stage, suggesting a general loss of circadian organization in the absence of the cues from the LD cycle. The details provided by the continuous activity record show that this disintegration of the rhythms can occur gradually over many weeks, possibly due to dissociation of the underlying circadian oscillators that regulate the rhythm.

The period of the free-running activity rhythm initially observed in the rams under DD was less than $24 \mathrm{hr}$ in seven or eight rams monitored continuously. This is consistent with our previous observation that the period of the free-running melatonin rhythm in rams is also less than $24 \mathrm{hr}$ (Almeida and Lincoln, 1984a). It is also of interest that the 1-hr light pulse (LD 1:23) was able to entrain the melatonin rhythm and the activity rhythm to produce a temporal relationship similar to that observed under the LD 8:16 and 16:8 photocycles. For example, under LD 1:23, the end of the period of increased activity preceded the time of lights-off and the onset of the melatonin peak with a similar relationship as seen under LD 8:16 (e.g., Figs. 2 and $5 b$ ). The 1-hr light pulse therefore appeared to act as the dusk signal, entraining both the activity and melatonin rhythms. It might be predicted that such a short light 
pulse should act as a dusk cue for rhythms that have a period of less than $24 \mathrm{hr}$, since the light pulse would encroach into the early subjective night and fall on the delay region of the phase response curve for the rhythm, leading to stable entrainment.

There was no evidence of free-running activity rhythms in the rams exposed to LL; however, some animals showed a significant low-amplitude rhythm with a period close to $24 \mathrm{hr}$ and an onset of activity from 0800 to $1000 \mathrm{hr}$ (Figs. 2a and 4c). This is more likely to represent an induced effect on the activity patterns from external cues rather than the persistence of an endogenous rhythm. One cue may have come from the necessity to enter the sheep housing to replenish water and to monitor the health of the rams. Also, there may well have been influences from the rams in an adjoining room, which were on a different light cycle with lights-on at $0800 \mathrm{hr}$. It is not clear why these factors only influenced some of the rams on LL and none on DD. Clearly, it would be preferable in future studies to monitor activity rhythms in sheep housed in greater isolation.

Although significant melatonin peaks were evident after 8 weeks under LL in the rams in Group 1 pretreated with LD 16:8, there was no clear evidence of regular periodicity or duration. Furthermore, melatonin peaks were not observed in the Group 2 rams pretreated with LD 8:16. We have previously observed persistent melatonin rhythms in rams for up to 10 days under LL (Almeida and Lincoln, 1984a); however, other studies in female sheep of other breeds have shown that LL can totally suppress melatonin secretion (Rollag and Niswender, 1976; Kennaway et al., 1983). The direct effects of light appear to depend on intensity (Lewy et al., 1980; Brainard et al., 1982), on the previous history of exposure to different light intensities (Reiter et al., 1983), and on the time the light is given relative to the phase of the endogenous melatonin rhythm. In this regard, light pulses early in the dark phase may only transiently suppress melatonin secretion (Reiter $\mathrm{et} \mathrm{al.,} \mathrm{1982;} \mathrm{Lincoln} \mathrm{et} \mathrm{al.,}$ 1985), whereas light pulses late in the dark phase may completely suppress melatonin secretion for the remainder of the night (Brinklow et al., 1984; Earl et al., 1985). In the current study, a 1-hr light pulse given after 8 weeks' exposure to DD had very little immediate effect on plasma melatonin concentrations but was a potent zeitgeber when repeated daily for 2 weeks. This suggests that, under our experimental conditions, the principal effect of light on melatonin secretion is entrainment rather than a direct effect.

It was predicted that the reproductive responses under the various photoperiod treatments would be explicable in terms of the patterns of melatonin secretion, because several studies in the ewe and in the Djungarian hamster have provided evidence that it is the duration of melatonin secretion by the pineal gland that transduces the effects of photoperiod to the reproductive axis (Bittman et al., 1983; Carter and Goldman, 1983; Bittman and Karsch, 1984; Goldman, et al., 1984; Wayne et al., 1988). This appears to be the case in the rams exposed to the standard change in photoperiod from LD 8:16 to 16:8. There was a significant reduction in the duration of the nocturnal melatonin peak and the predicted decline in the activity of the reproductive axis characteristic of exposure to an inhibitory long-day photoperiod or exposure to a short-duration daily treatment with melatonin. However, under the DD and LL photoperiods, it was not possible to account for the reproductive 


\section{ACTIVITY AND MELATONIN RHYTHMS IN RAMS}

changes in terms of the daily patterns of melatonin secretion, since the melatonin rhythms were poorly defined or absent. Judging from the changes in plasma concentrations of FSH and size of the testes, exposure to DD resulted in short-day responses both in sexually inactive rams pretreated with LD 16:8 (rapid redevelopment of the reproductive axis as under LD 8:16) and in sexually active rams pretreated with LD 8:16 (slow regression of the reproductive axis; see Almeida and Lincoln, 1984b). In contrast, exposure to LL appeared to result in long-day responses in sexually active rams pretreated with LD 8:16 (rapid regression of the reproductive axis as under LD 16:8) but resulted in short-day responses in sexually inactive rams pretreated with LD 16:8 (rapid redevelopment of the reproductive axis as under LD 8:16). This last result is particularly surprising since it might be predicted that LL would be interpreted as a long day, and thus, testicular development would be delayed. This was the case in a previous study (Almeida and Lincoln, 1984b); testicular regression was initially induced in Soay rams by long-day (LD 16:8) treatment. The rams were subsequently maintained on the same photoperiod. Testicular recrudescence occurred on the long-day photoperiod, but maximum testis diameter took 16-24 weeks to occur on LD 16:8, as compared with 8-12 weeks on LL in the current study. In addition to showing rapid testicular development on LL, the testes of the rams in the current study regressed rapidly when the rams were subsequently transferred back to a LD 16:8 photoperiod (data not shown). The observation that LL treatment restores sensitivity to the inhibitory effects of a LD 16:8 photoperiod provides further evidence that LL treatment does not provide a long-day signal when it is given following a LD 16:8 pretreatment period.

It is interesting to note that all the rams had significant melatonin peaks on LL when it followed LD 16:8 pretreatment, but none had peaks when LL followed LD $8: 16$ pretreatment. Although the mean duration of these melatonin peaks was only $12.4 \mathrm{hr}$, this was longer than the previous nocturnal duration on LD 16:8. An increase in the duration of nocturnal melatonin secretion of only $3 \mathrm{hr}$ is sufficient to provide a short-day signal for reproductive activity in female sheep (Robinson and Karsch, 1987) so it is conceivable that the modest increase in the duration of the melatonin peaks on LL provided short-day information to the rams and stimulated rapid testicular recrudescence. However, the duration of these melatonin peaks on LL was very variable both within and between rams, and the period between successive peaks was not close to $24 \mathrm{hr}$ (Fig. 6a), so it is questionable whether the observed reproductive responses really resulted from changes in the pattern of melatonin secretion.

It is likely that in the absence of clear photoperiodic information in the form of melatonin secretion, reproductive changes in the sheep are entirely dictated by their previous photoperiod history. Several studies have demonstrated that when sheep are maintained for a prolonged period on a long-day photoperiod, after the acute inhibitory effects of such photoperiods, reproductive activity ensues; that is, the sheep becomes refractory to the long-day photoperiod (Worthy et al., 1985; Almeida and Lincoln, 1984b; Robinson et al., 1985; Jackson et al., 1988). Conversely, sheep maintained for a prolonged period on a short-day photoperiod become refractory to its stimulatory effects, and reproductive regression occurs (Lincoln, 1980; Worthy 
and Haresign, 1983; Almeida and Lincoln, 1984b; Robinson and Karsch, 1984; Jackson et al., 1988). Photorefractoriness probably results from refractoriness to the melatonin signal, since sheep become refractory to the inductive effects of melatonin implant treatments and to nocturnal melatonin infusions, which provide a short-day signal (Lincoln and Ebling, 1985; Karsch et al., 1986). It has been hypothesized that refractoriness in sheep represents the expression of an endogenous reproductive rhythm (Robinson et al., 1985), because sheep maintained for an extended period of time on a fixed photoperiod continue to show long-term fluctuations in reproductive activity after the initial period of acute response and refractoriness (Howles et al., 1982; Almeida and Lincoln, 1984b; Karsch et al., 1987). However, it is not clear whether such long-term rhythms reflect the activity of an endogenous circannual oscillator or simply the repetition of a series of timed stages (Enright, 1970; Mrosovsky, 1970). Whatever the basis of these long-term rhythms, they may explain the reproductive changes observed in the current study. It appears that the rams were already developing refractoriness to both the stimulatory effects of LD 8:16 and to the inhibitory effects of LD 16:8 by the end of the 16-week pretreatment periods (Fig. 7). The reproductive responses subsequently observed on LL and DD would, therefore, have been largely determined by the previous photoperiod treatment. The ambient photoperiod might be expected to modify to a small degree the rate of testicular change but not to prevent completely testicular regression or recrudescence. Indeed, it is clear that reproductive changes can occur in the absence of a melatonin signal, providing that the sheep has obtained an adequate photoperiodic history. For example, puberty occurs in the female sheep at the normal time of year even if the nocturnal rise in melatonin secretion has been abolished by superior cervical ganglionectomy, providing that an appropriate seasonal time cue has been given prior to surgery (Foster et al., 1988a, 1988b).

In conclusion, we have provided the first evidence in sheep that changes in circadian rhythms in melatonin secretion occur in close parallel with changes in circadian rhythms in activity. Both rhythms are affected by transfer from LD 8:16 to 16:8, become disrupted after prolonged exposure to DD or LL, and can be entrained in a normal temporal relationship by exposure to a short light pulse given every 24 $\mathrm{hr}$ under DD. It is proposed that the continuous monitoring of activity combined with short-term studies on the daily pattern of melatonin secretion is a useful approach to investigate the circadian basis of photoperiodic responses in sheep.

\section{ACKNOWLEDGMENTS}

We thank Rhona Cunningham and Lorna Downey for help with serial blood sample collections; Mr. R. Bayne and Mr. A Speed for help with activity recording equipment; Hazel Ebling and Pamela Holland for help with digitizing activity records; Pam Warner for statistical advice; Drs. G. D. Niswender, M. Rollag, and A. S. McNeilly for antiserum for melatonin and FSH radioimmunoassays; the NIADDK for FSH standards; and Diane Belleba and Betty Lewis for secretarial support.

\section{REFERENCES}

Almeida, O. F. X., and G. A. Lincoln (1982) Photoperiodic regulation of reproductive activity in the ram: Evidence for the involvement of cir- cadian rhythms in melatonin and prolactin secretion. Biol. Reprod. 27: 1062-1075.

Almeida, O. F. X., and G. A. Lincoln (1984a) 


\section{ACTIVITY AND MELATONIN RHYTHMS IN RAMS}

Central mechanisms in the control of seasonal breeding. Acta Zool. Fennica. 171: 151-156.

AlmeidA, O. F. X., and G. A. Lincoln (1984b) Reproductive refractoriness in rams and accompanying changes in the patterns of melatonin and prolactin secretion. Biol. Reprod. 30: 143-158.

Bittman, E. L., J. Dempsey, and F. J. Karsch (1983) Pineal melatonin secretion drives the reproductive response to daylength in the ewe. Endocrinology 113: 2276-2283.

Bittman, E. L., and F. J. Karsch (1984) Nightly duration of pineal melatonin secretion determines the reproductive response to inhibitory day lengths in the ewe. Biol. Reprod. 30: 585593.

Brainard, G. C., B. A. Richardson, L. T. PetTERBORG, and R. J. REITER (1982) The effect of different light intensities on pineal melatonin content. Brain Res. 233: 75-81.

BRINKLOW, B. R., J. M. Forbes, and R. G. RoDWAY (1984) Melatonin in the plasma of growing sheep subjected to short and skeleton long photoperiods. Experientia 40: 758-760.

Carter, D.S., and B. D. Goldman (1983) Antigonadal effects of timed melatonin infusion in pinealectomized male Djungarian hamsters (Phodopus sungorus sungorus): Duration is the critical parameter. Endocrinology 113: 12611267.

EARL, C. R., M. J. D'OCChIO, D. J. Kennaway, and R. F. SEAMARK (1985) Serum melatonin profiles and endocrine responses of ewes exposed to a pulse of light late in the dark phase. Endocrinology 117: 226-230.

Eisemann, J. H., D. E. Bauman, D. E. Hogue, and H. F. TRAvis (1984) Evaluation of a role for prolactin in growth and the photoperiod-induced growth response in sheep. J. Animal Sci. 59: 8694.

Elliotr, J. A. (1976) Circadian rhythms and photoperiodic time measurement in mammals. Fed. Proc. 35: 2339-2346.

Ellis, G. B., and F. W. TuREK (1979) Changes in locomotor activity associated with the photoperiodic response of the testes in male golden hamsters. J. Comp. Physiol. 132: 277-284.

ENRIGHT, J. T. (1970) Ecological aspects of endogenous rhythmicity. Ann. Rev. Ecol. Sys. 1: 231238.

Eskes, G. A., and I. ZuCKer (1978) Photoperiodic regulation of the hamster testis: Dependence on circadian rhythms. Proc. Natl. Acad. Sci. USA 75: $1034-1038$.

Foster, D. L., S. M. Yellon, F. J. P. Ebling, and L. E. Claypool (1988a) Are ambient shortday cues necessary for puberty in a short-day breeder? Biol. Reprod. 38: 821-829.

Foster, D. L., F. J. P. Ebling, L. E. Claypool, and C. J. I. Woodfill (1988b) Cessation of long day melatonin rhythms time puberty in a short day breeder. Endocrinology 123: 1636-1641.

Goldman B. D., J. M. Darrow, and L. Yogev (1984) Effects of timed melatonin infusions on reproductive development in the Djungarian hamster (Phodopus sungorus). Endocrinology 114: 2074-2083.

Gordon, J. G., and I. K. McAlistair (1970) The circadian rhythm of rumination. J. Agric. Sci. (Camb.) 74: 291-297.

Howles, C. M., J. Craigon, and N. B. Haynes (1982) Long term rhythms of testicular volume and plasma prolactin concentrations in rams reared for three years in constant photoperiod. $J$. Reprod. Fert. 65: 439-446.

Hughes, G. P., and D. Reid (1951) Studies on the behaviour of cattle and sheep in relation to the utilization of grass. J. Agric. Sci. (Camb.) 41 : 350-366.

HUNSAKER, W. G., and M. S. Wolynetz (1979a) Vaginal temperature and eating, drinking, standing and walking activity rhythms of four anoestrous Finnish-Landrace ewes. Can. J. Animal Sci. 59: 11-53.

HUNSAKer, W.G., and M. S. Wolynetz (1979b) A study of free-running rhythms in sheep. Int. J. Chronobiol. 6: 219-230.

Illnerova, H., and J. VANeCEK (1982) Twooscillator structure of the pacemaker controlling the circadian rhythm of $\mathrm{N}$-acetyltransferase in the rat pineal gland. J. Comp. Physiol. 145: 539548.

JaCkson, G. L., M. Gibson, and D. Kuehl (1988) Photoperiodic disruption of photorefractoriness in the ewe. Biol. Reprod. 38: 127-134.

Karsch, F. J., E. L. Bittman, D. L. Foster, R. L. Goodman, S. J. Legan, and J. E. RobINSON (1984) Neuroendocrine basis of seasonal reproduction. Rec. Prog. Horm. Res. 40: 185232.

Karsch, F. J., E. L. Bittman, J. E. Robinson, S. M. Yellon, N. L. WAYNE, and A. H. KaYNARD (1986) Melatonin and photorefractoriness: Loss of response to the melatonin signal leads to seasonal reproductive transitions in the ewe. Biol. Reprod. 34: 265-274.

KARSCh, F. J., J. E. Robinson, and C. J. I. WoODFILL (1987) Existence of an endogenous reproductive rhythm in the ewe. Endocrinology 120(suppl): 262.

Kennaway, D. J., L. Sanford, B. Godfrey, and H. G. FRIESEN (1983) Patterns of progesterone, melatonin and prolactin secretion in ewes maintained in four different photoperiods. J. Endocrinol. 97: 229-242.

LeWy, A. J., T. A. Wehr, F. K. GoOdWIN, D. A. NewSOME, and S. P. MARKely (1980) Light suppresses melatonin secretion in humans. Science 210: 1267-1269. 
Lincoln, G.A. (1980) Photoperiodic control of seasonal breeding in rams-The significance of short-day refractoriness. In Endocrinology 1980 , J. W. Funder and F. A. O. Mendelsohn, eds., pp. 283-286, Australian Academy of Sciences, Canberra, Australia.

Lincoln, G. A., and W. Davidson (1977) The relationship between sexual and aggressive behaviour and pituitary and testicular activity during the seasonal sexual cycle of rams and the influence of photoperiod. J. Reprod. Fert. 49: 267276.

Lincoln, G. A., and F. J. P. EBLING (1985) Effect of constant-release implants of melatonin on seasonal cycles in reproduction, prolactin secretion and moulting in rams. J. Reprod. Fert. 73: 241253.

Lincoln, G. A., F. J. P. Ebling, and O. F. X. Almeida (1985) Generation of melatonin rhythms. In Photoperiodism, Melatonin and the Pineal (Ciba Foundation Symposium 117), pp. 129-148, Pitman, London.

McNeIlly, J. R., A. S. McNeilly, J. S. WALTON, and F. J. Cunningham (1976) Development and application of a heterologous radioimmunoassay for ovine follicle-stimulating hormone. J. Endocrinol. 70: 69-79.

Mrosovsky, N. (1970) Mechanism of hibernation cycles in ground squirrels: Circannual rhythm or sequence of stages? Penn. Acad. Sci. 44: 172175.

ReIter, R. J., T. S. KING, B. A. RichaRdson, and E. C. Hurlbut (1982) Studies on pineal melatonin levels in a diurnal species, the Eastern chipmunk (Tamias striatus). Effects of light at night, propranolol administration, or superior cervical ganglionectomy. J. Neural. Trans. 54: 275-284.

Reiter, R. J., S. Steinlechner, B. A. RichardsoN, and T. S. KING (1983) Differential response of pineal melatonin levels to light at night in laboratory-raised and wild-captured thirteen-lined ground squirrels. Life Sci. 32: 2625-2629.

Robinson, J. E., and F. J. KARSCH (1984) Refractoriness to inductive day lengths terminates the breeding season of the Suffolk ewe. Biol. Reprod. 31: 656-663.

Robinson, J. E., and F. J. Karsch (1987) Photo- periodic history and a changing melatonin pattern can determine the neuroendocrine response of the ewe to daylength. J. Reprod. Fert. 80 : 159-165.

Robinson, J. E., N. L. WAYNE, and F. J. KARSCH (1985) Refractoriness to inhibitory day lengths initiates the breeding season of the Suffolk ewe. Biol. Reprod. 32: 1024-1030.

Rollag, M. D., and G. D. Niswender (1976) Radioimmunoassay of serum concentrations of melatonin in sheep exposed to different lighting regimens. Endocrinology 98: 482-489.

SiEGEl, S. (1956) Non-parametric Statistics, McGraw-Hill, New York.

Sokolove, P.G., and W. N. Bushell (1978) The chi square periodogram: Its utility for analysis of circadian rhythms. J. Theor. Biol. 72: 131-160.

TUREK, F. W., D. J. EARnEST, and J. SWANN (1982) Splitting of the circadian rhythm of activity in hamsters. In Vertebrate Circadian Systems, J. Aschoff, S. Daan, and G. Groos eds., pp. 203214, Springer-Verlag, Berlin.

WAtSOn-WhitMyre, M., and M. H. Stetson (1983) Simulation of peak melatonin release restores sensitivity to evening melatonin injections in pinealectomized hamsters. Endocrinology 112: 763-765.

Wayne, N. L., B. Malpaux, and F. J. Karsch (1988) How does melatonin code for day length in the ewe: Duration of nocturnal melatonin release or coincidence of melatonin with a lightentrained sensitive period? Biol. Reprod. 39: 66-75.

WollNiK, F., and K-D. DöhleR (1986) Effect of adult or perinatal hormonal environment on ultradian rhythms in locomotor activity of laboratory LEW/Ztm rats. Physiol. Behav. 38: 229240.

Worthy, K., and W. Haresign (1983) Evidence that the onset of seasonal anoestrus in the ewe may be independent of increasing prolactin concentrations and daylength. J. Reprod. Fert. 69: 41-48.

Worthy, K., W. Haresign, S. Dodson, B. J. MCLEOD, G. R. Foxcroft, and N. B. HAYNES (1985) Evidence that the onset of the breeding season in the ewe may be independent of decreasing prolactin concentrations. J. Reprod. Fert. 75: 237-246. 